\title{
Stainless steel matrix composites reinforced with ceramic particles through ingot casting process
}

\author{
Ana Kračun ${ }^{1,2, *}$, Franc Tehnovnik ${ }^{1}$, Fevzi Kafexhiu ${ }^{1}$, Tadeja Kosec $^{3}$, Darja Jenko ${ }^{1}$, and \\ Bojan Podgornik ${ }^{1}$ \\ ${ }^{1}$ Institute of Metals and Technology, Lepi pot 11, 1000 Ljubljana, Slovenia \\ 2 Jožef Stefan International Postgraduate School, Jamova 39, 1000 Ljubljana, Slovenia \\ ${ }^{3}$ Slovenian National Building and Civil Engineering Institute, Dimičeva ulica 12, 1000 Ljubljana, \\ Slovenia.
}

\begin{abstract}
The aim of the study was to assess the influence of adding $\mathrm{Al}_{2} \mathrm{O}_{3}$ nano-particles of $0.5 \mathrm{wt}$. \% with the mean particle size of $500 \mathrm{~nm}$ on the mechanical properties and wear behaviour of the austenitic stainless steel matrix reinforced with nano-particles produced by conventional ingot casting. The focus was on the methods and possibilities of homogeneous and uniform distribution of the particles within the steel matrix using conventional casting routes. The main drawback of the casting method used is the agglomeration of the particles and poor interface between the particles and the metal matrix. The results show that through a proper insertion method, nano-particles can be successfully introduced into the metal matrix. The $\mathrm{Al}_{2} \mathrm{O}_{3}$ nano-particles were successfully incorporated into the steel matrix with no signs of clustering and intermetallic reactions taking place between the nano-particles and the steel matrix. This led to improved mechanical properties as well as the wear behaviour of the stainless steel, achieved by using conventional casting routes.
\end{abstract}

\section{Introduction}

Austenitic stainless steel alloys are known for their excellent resistance to corrosion and high ductility, and are therefore used in the aerospace, defence, and biomedical domains [1]. However, even though austenitic stainless steels are widely used materials, their mechanical properties and wear resistance could be further improved. Strategies to achieve this goal have entailed incorporating secondary phases such as ceramic particulates with sizes in the micron range at the matrix grain boundaries [2]. However, the results have been disappointing $[3,4]$, owing to the limited degree of interfacial wetting between the ceramic particulates and the metal. Basically, the large ceramic particles are prone to cracking during mechanical loading, resulting in poor ductility and the premature failure of the material $[5,6]$.

\footnotetext{
*Corresponding author: ana.kracun@imt.si
} 
Metal matrix nanocomposites (MMnCs) have been recently incorporated as a nanometersized secondary phase dispersion in the metal matrix [7,8]. Indeed, most nanostructured materials are fundamentally different from conventional polycrystalline ones and lead to improvements in parameters such as the yield strength, toughness, and hardness because of the resulting microstructural refinement $[5,6,9]$. The use of these materials as reinforcing secondary phases is likely to improve the performance of steel alloys with respect to engineering applications such as gas turbines, automobiles, and biomedical devices [10, 11]. To achieve the desired mechanical properties of nanocomposites, reinforcing nanoparticles must be distributed uniformly within the metal matrix of the composite. However, homogeneous dispersion of ceramic nano-particles in metals is difficult to achieve using conventional production routes. The nano-particles tend to agglomerate into coarse clusters during liquid metallurgy processing. This is due to poor wettability of nano-particles with large surface areas in molten metals.

The aim of the present study was to investigate possibilities of introducing nano-particles into the steel matrix through conventional casting route. This production route seems to show potential and offers more cost efficiency in achieving the dispersion of the secondary phase through ultrafine particles as compared to the powder and metallurgical techniques used until now. The aim of this work was therefore to study the influence of the reinforcing $\mathrm{Al}_{2} \mathrm{O}_{3}$ nano-particles on the microstructure of a steel matrix when introduced using a conventional casting method, as well as to determine their effect on the mechanical and anti-wear properties of the stainless steel nano-composite.

\section{Experimental work}

\subsection{Materials}

$\mathrm{Al}_{2} \mathrm{O}_{3}$ powder with a mean particle size of $500 \mathrm{~nm}$ and the austenitic stainless steel AISI 316 with the chemical composition given in Table 1 were used as starting materials.

Table 1: Chemical composition of the base austenitic stainless steel in wt \%

\begin{tabular}{|c|c|c|c|c|c|c|c|}
\hline$\% \mathrm{C}$ & $\% \mathrm{Si}$ & $\% \mathrm{Mn}$ & $\% \mathrm{Cu}$ & $\% \mathrm{Cr}$ & $\% \mathrm{Ni}$ & $\% \mathrm{Mo}$ & $\% \mathrm{~V}$ \\
\hline 0.02 & 0.33 & 1.24 & 0.36 & 17.4 & 10.1 & 1.29 & 0.08 \\
\hline
\end{tabular}

Commercial $\mathrm{Al}_{2} \mathrm{O}_{3}$ powder from the company US Research Nanomaterials, Inc. with a mean particle size of $500 \mathrm{~nm}$ were used as reinforcement particles.

\subsection{Specimen preparation}

A weighted quantity $(24 \mathrm{~kg})$ of the austenitic stainless steel was melted in an induction furnace under the normal atmospheric conditions followed by casting in the steel moulds combined with $\mathrm{Al}_{2} \mathrm{O}_{3}$ nano-particles addition. The mass of each cast ingot was $8 \mathrm{~kg}$. The material was investigated in three different conditions: $\mathrm{R}$ - reference material in cast and hot rolled state, A1 - cast and hot rolled material with the addition of 0.5 wt. $\% \mathrm{Al}_{2} \mathrm{O}_{3}$ powder and $\mathrm{A} 2$ - cast and hot rolled material with the addition of $0.5 \mathrm{wt} . \% \mathrm{Al}_{2} \mathrm{O}_{3}$ powder mixed with the dispersion media - CaSi in 1:1 mass ratio. Before casting the $\mathrm{Al}_{2} \mathrm{O}_{3}$ nanoparticles, powder mixture was filled into a ferritic iron tube and the ends of the tube sealed 
with pliers. The sealed iron tube was then placed in the mould and the molten metal poured over it. In all cases the iron tube was melted and dissolved in the melt completely.

\subsection{Metallographic characterization}

The microstructural changes and the dispersion of the ceramic particles in the steel matrix were observed and analysed by light microscopy (LM), scanning electron microscopy (SEM), and transmission electron microscopy (TEM). Samples for microstructure analysis were taken from the middle portion of the cast ingot. Metallographic samples were prepared by grinding with $\mathrm{SiC}$ paper, followed by polishing with $1 \mu \mathrm{m}$ diamond suspension.. All the specimen surfaces were in addition cleaned with alcohol and dried with hot air. For representative analysis of particles distribution, a surface area of $1 \mathrm{~mm} \times 1 \mathrm{~mm}$ was analysed on at least five parallel samples using the INCA Feature software incorporated in the SEM, which provides an automatic high performance feature detection, analysis, and classification of microscopic particles. Samples for the Transmission Electron Microscopy were prepared by slicing the specimens into thin foils $(0.5-1.0 \mathrm{~mm})$ with a length of up to $3 \mathrm{~mm}$. After polishing the foils down to a thickness of $100 \pm 10 \mu \mathrm{m}$, final milling was carried out by Ion Slicer.

\subsection{Mechanical properties and wear behaviour}

Vickers hardness measurements of the investigated samples reinforced with $\mathrm{Al}_{2} \mathrm{O}_{3}$ nanoparticles were measured using the Instron Tukon 2100B machine with a load of $9.807 \mathrm{~N}$ (HV1). The impact toughness tests were performed using the standard Charpy V-notch test specimens. Tensile tests were performed on the INSTRON 1255 test machine using the standard type B tensile test specimens (DIN 50125:2009-07). All mechanical properties were evaluated at the room temperature using at least three parallel specimens. Tribological tests were carried out under dry reciprocating sliding contact at the room temperature using TRIBOtechnic Pin-on-Disc TRIBOtester. We selected three sets of test conditions to determine how the material behaves under different loads and sliding speeds. A hardened stainless steel ball (X47Cr14) with a diameter of $10 \mathrm{~mm}$ and hardness of 490 HV1 was used as a loading counter-body. All test parameters are presented in Table 2. In order to establish the test-to-test repeatability of the data, each friction/wear test was repeated three times. The coefficient of friction was measured continuously during the test and the wear volume was determined using the $3 \mathrm{D}$ optical profilometer (Alicona Infinite Focus G4) after the completion of the test., A new ball was used for each test and both the specimen and the counter body were washed in a high purity acetone and dried in air prior to testing.

Table 2: Wear test parameters used

\begin{tabular}{|c|c|c|c|}
\hline Counter body & \multicolumn{4}{|c|}{ hardened stainless steel ball } \\
\hline Constant load Fn (N) & 1 & 3 & 3 \\
\hline Hertz contact pressure [MPa] & 470 & 675 & 675 \\
\hline Sliding speed [mm/s] & 20 & 20 & 2 \\
\hline Amplitude [mm] & \multicolumn{4}{|c|}{5} \\
\hline Frequency[Hz] & 2 & 2 & 0.2 \\
\hline
\end{tabular}




\begin{tabular}{|c|r|r|r|} 
Test time $[\mathrm{s}]$ & 300 & 300 & 3000 \\
\hline Sliding distance $[\mathrm{m}]$ & \multicolumn{3}{|c|}{6} \\
\hline
\end{tabular}

\section{Results and Discussion}

\subsection{Microstructural characterization}

Preliminary microstructure studies of Kračun et al. [12] were largely focused on the microstructure of quenched pure austenitic stainless steel. From the LM micrographs it was established that the matrix consists of a distinctive two-phase microstructure of austenite and $\delta$-ferrite. In order to confirm the type of reinforced nano-particles, the investigated specimens were characterized by energy-dispersive X-ray spectroscopy (EDS) analysis. To show the morphology and size of $\mathrm{Al}_{2} \mathrm{O}_{3}$ particles clearly, the etched samples of as cast austenitic stainless steel reinforced with $\mathrm{Al}_{2} \mathrm{O}_{3}$ nano-particles were examined by SEM as shown in Figure 1. It can be clearly seen from Fig. 1a that $\mathrm{Al}_{2} \mathrm{O}_{3}$ nano-particles are incorporated but non-uniformly distributed in the matrix, with pronounced particles clustering being observed in the case of experiment $\mathrm{A} 1$ involving only $\mathrm{Al}_{2} \mathrm{O}_{3}$ nano-particles powder. However, when $\mathrm{Al}_{2} \mathrm{O}_{3}$ nano-particles are mixed with dispersant (experiment $\mathrm{A} 2$ ), they are uniformly distributed in the matrix, as shown in Fig. 1 b.

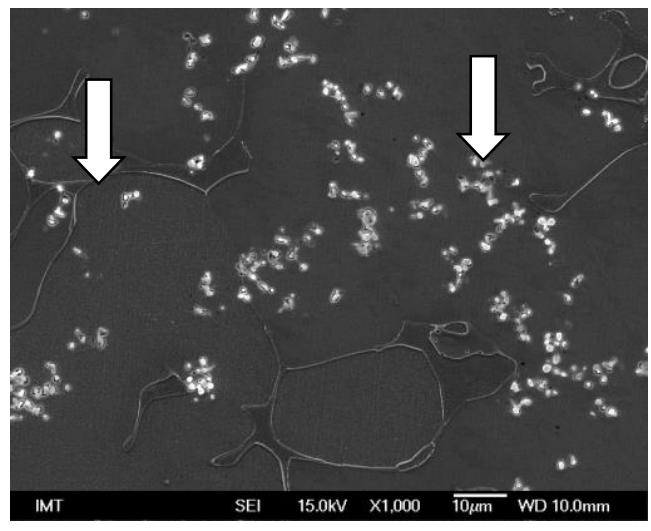

(a)

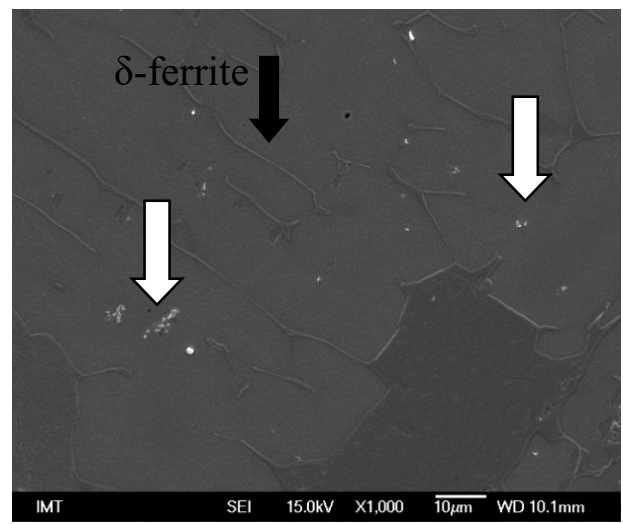

(b)

Figure 1: Cast microstructure of austenitic stainless steel at a 1,000x magnification with $6 \%$ of $\delta$ ferrite and added $0.5 \mathrm{wt} \%$ of $\mathrm{Al}_{2} \mathrm{O}_{3}$ nanoparticles; (a) solely $\mathrm{Al}_{2} \mathrm{O}_{3}$ nanoparticles (experiment $\mathrm{A} 1$ ) and (b) $\mathrm{Al}_{2} \mathrm{O}_{3}$ nanoparticles mixed with $\mathrm{CaSi}$ (experiment $\mathrm{A} 2, \mathrm{Al}_{2} \mathrm{O}_{3}: \mathrm{CaSi}=1: 1$ ).

Using STEM line profile analyses shown in the Figure 2, it was confirmed that the incorporation and the coherent bonding of the $\mathrm{Al}_{2} \mathrm{O}_{3}$ nanoparticles in the steel matrix was successful. No discontinues at the particle/matrix interface, modification of metal matrix or formation of intermetallic phases could be observed. 

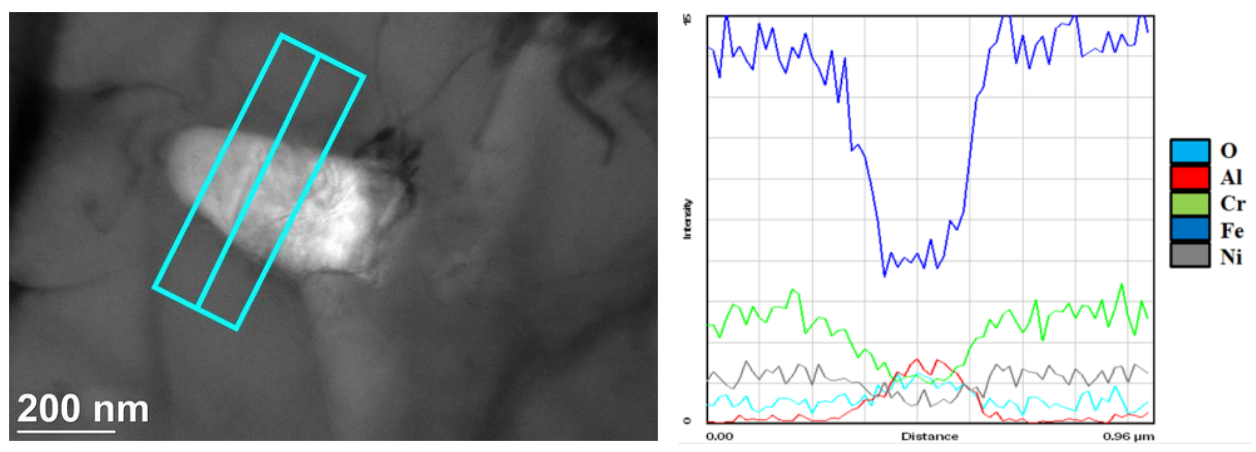

Figure 2: STEM - line profile of $\mathrm{Al}_{2} \mathrm{O}_{3}$ nano-particle ( $500 \mathrm{~nm}, 0.5$ wt.\%, experiment $\left.\mathrm{A} 1\right)$ in the cast microstructure of austenitic stainless steel.

By using $\mathrm{CaSi}$ as a dispersion media and introducing $\mathrm{Al}_{2} \mathrm{O}_{3} / \mathrm{CaSi}$ mixture through a sealed ferritic iron tube, reduced particles clustering and provided more homogeneous distribution of reinforcing nano-particles in the steel matrix, (Fig. $1 \mathrm{~b}$ ). This made the automatic analysis of particles distribution using the INCA Feature $(1 \mathrm{~mm} \times 1 \mathrm{~mm}$ surface $)$ possible. At the nano-particle mass fraction of $0.5 \mathrm{wt} \%$, the number of incorporated $\mathrm{Al}_{2} \mathrm{O}_{3}$ nanoparticles per unit area $\left(\mathrm{mm}^{2}\right)$ was 2510 and the surface fraction of $\mathrm{Al}_{2} \mathrm{O}_{3}$ nano-particles was $0.28 \%$. Size-dependent analysis of incorporating $\mathrm{Al}_{2} \mathrm{O}_{3}$ nano-particles indicate that particles are in the size class from $300 \mathrm{~nm}$ to $1 \mu \mathrm{m}$, as shown in Fig. 3. In the case of using the pure $\mathrm{Al}_{2} \mathrm{O}_{3}$ nano-particles powder without any dispersion agent, the nano-particles were agglomerated, therefore, the size distribution analysis by applying the INCA Feature was not possible.

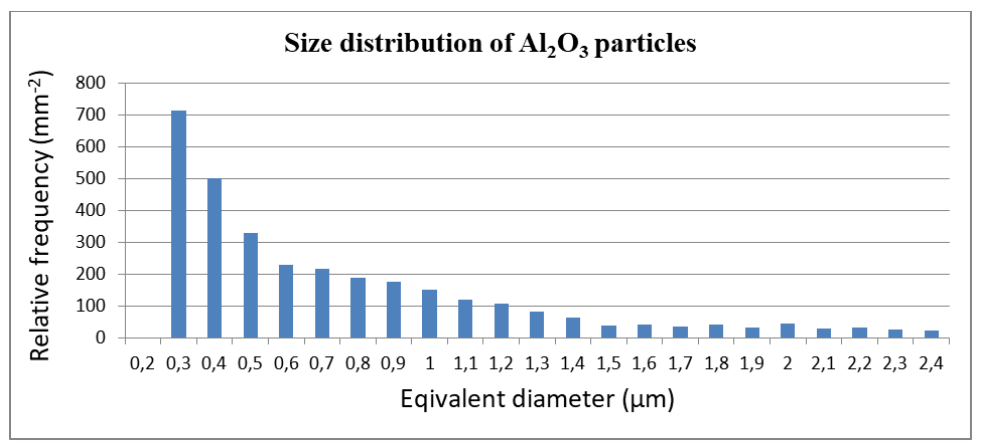

Figure 3: INCA Feature size distribution analysis of $\mathrm{Al}_{2} \mathrm{O}_{3}$ nano-particles added in the form of mixture with $\mathrm{CaSi}\left(0.5 \mathrm{wt} \% ; \mathrm{Al}_{2} \mathrm{O}_{3}: \mathrm{CaSi}=1: 1\right)$.

\subsection{Hardness and impact toughness}

The hardness and impact toughness results for stainless steel reinforced with $\mathrm{Al}_{2} \mathrm{O}_{3}$ nanoparticles without $\mathrm{CaSi}$ (A1) or with (A2) CaSi dispersant are shown in Fig. 4a. An observed hardness increase from 161 to $170 \mathrm{HV} 1$ is due to the reinforcing secondary phases of $\mathrm{Al}_{2} \mathrm{O}_{3}$ nano-particles. By mixing the $\mathrm{Al}_{2} \mathrm{O}_{3}$ nano-particles with $\mathrm{CaSi}$ dispersive media, which facilitates more homogeneous and uniform distribution of nano-particles in the steel 
matrix, additional increase in hardness of up to $185 \mathrm{HV} 1$ was obtained. With an increased hardness, the impact toughness dropped from 160 to 143 J. However, in the case of the Yield and Ultimate tensile strength, there are no major changes in values when introducing $\mathrm{Al}_{2} \mathrm{O}_{3}$ nanoparticles, as shown in Fig. $4 \mathrm{~b}$.

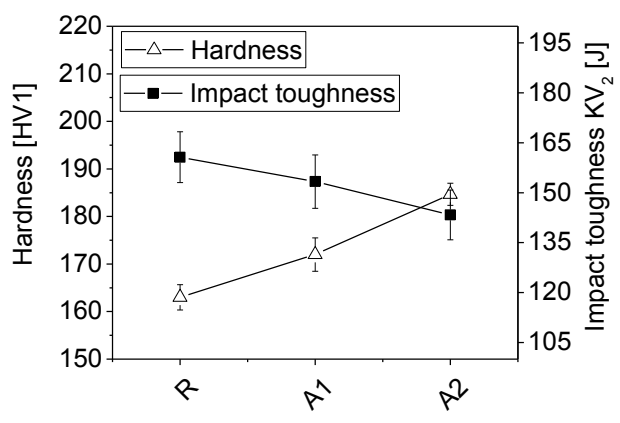

(a)

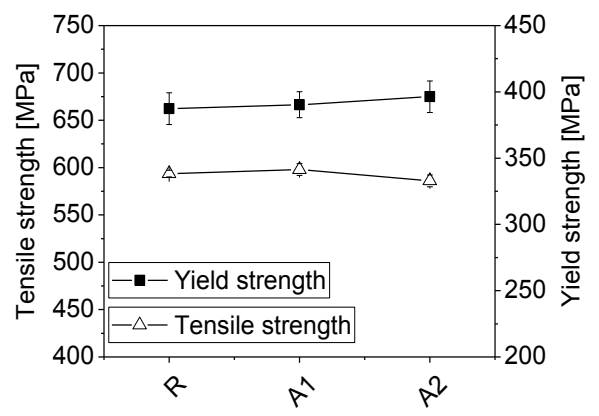

(b)

Figure 4: Change in mechanical properties for material investigated in three different experimental conditions - R, A1, A2; a) diagram for hardness and impact toughness and b) for ultimate tensile strength and yield strength.

\subsection{Wear results}

Tribological test results confirm that the hardest test specimen A2 also shows the highest wear resistance, as shown in Figure 5. With the addition of $\mathrm{Al}_{2} \mathrm{O}_{3}$ nanoparticles, the wear rate of austenitic stainless steel was reduced by more than an order of magnitude. The wear rate of the reference austenitic stainless steel was reduced from $2.0 \times 10^{-3} \mathrm{~mm}^{3} / \mathrm{Nm}$ down to 0.3-0.6 $\times 10^{-3} \mathrm{~mm}^{3} / \mathrm{Nm}$ when adding $\mathrm{Al}_{2} \mathrm{O}_{3}$ reinforcement nano-particles (Fig. 5). It is evident that $\mathrm{Al}_{2} \mathrm{O}_{3}$ nano-particles addition is beneficial in improving the wear resistance of the stainless steel due to the high hardness and better wear resistance of the reinforcing $\mathrm{Al}_{2} \mathrm{O}_{3}$ ceramic nano-particles. Furthermore, by obtaining a more homogeneous distribution of $\mathrm{Al}_{2} \mathrm{O}_{3}$ nanoparticles, facilitated by mixing nanoparticles with dispersive media (experiment A2), further reduction in the wear rate was obtained. In the case of the specimen A2, the wear rate was reduced down to $0.25-0.4 \mathrm{~mm}^{3} / \mathrm{Nm}$, as shown in Fig. 5 .

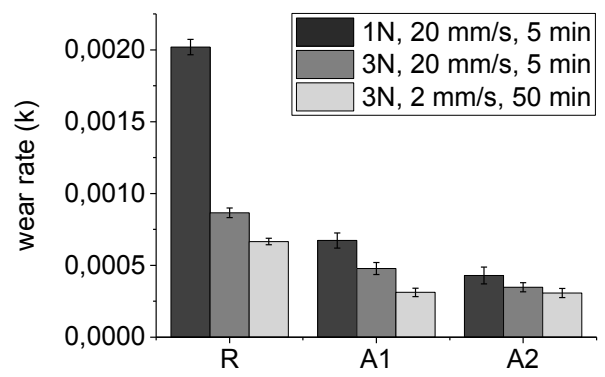

Figure 5: Wear rates for material investigated in three different experimental conditions - R, A1, A2.

SEI images of the wear tracks for the specimen reinforced with $0.5 \mathrm{wt} \% \mathrm{Al}_{2} \mathrm{O}_{3}$ nanoparticles and the addition of CaSi tested at a load of $3 \mathrm{~N}$ and sliding speed of $2 \mathrm{~mm} / \mathrm{s}$ are shown in Figure 6. For all specimens, the abrasive wear was found as the prevailing wear 
mechanism accompanied by plastic deformation and adhesive wear, observed especially at the edges of the wear scar (Fig. 6b).

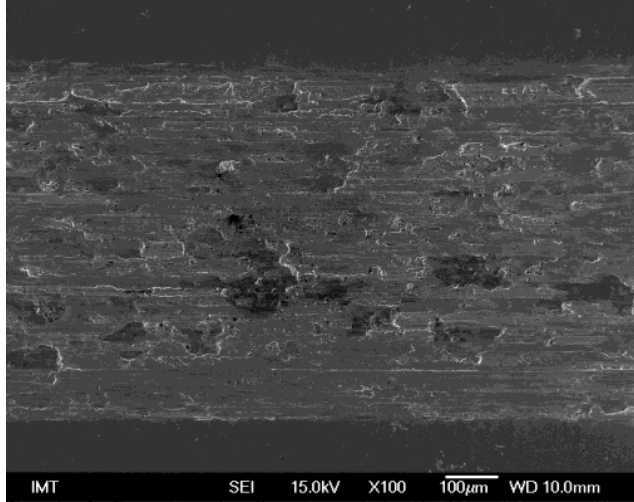

(a)

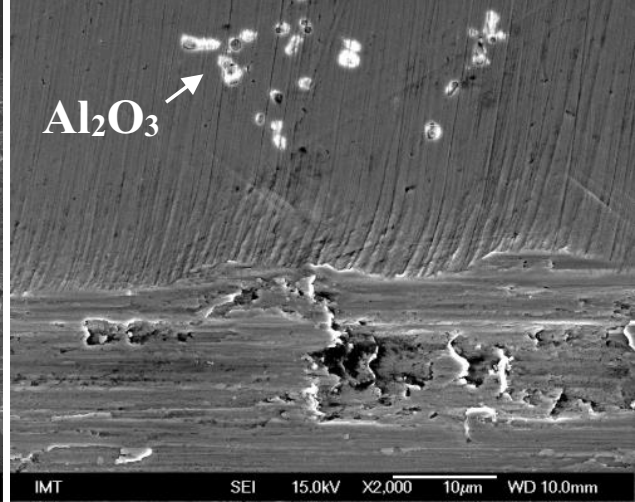

(b)

Figure 6: SEI image at a 100x and 2,000x magnifications of a wear tracks for specimen $\mathrm{A} 2$ tested for $3000 \mathrm{~s}$ at a load of $3 \mathrm{~N}$ and sliding speed of $2 \mathrm{~mm} / \mathrm{s}$.

SEM investigation of the wear tracks performed under backscattered electron (BSE) image mode revealed that the $\mathrm{Al}_{2} \mathrm{O}_{3}$ nano-particles are incorporated and uniformly distributed in the matrix in the case of the experiment A2, thus taking an active role in wear process by carrying the load and reducing wear. In addition, the more uniformly reinforcing particles are distributed, the better is their load support. To confirm the type of the reinforcing nanoparticles, the specimens were characterized by energy-dispersive X-ray spectroscopy (EDS) analysis, shown in Fig. 7. Spectra 1,2 and 3 represent $\mathrm{Al}_{2} \mathrm{O}_{3}$ nano-particles and spectrum 4 represent the matrix.

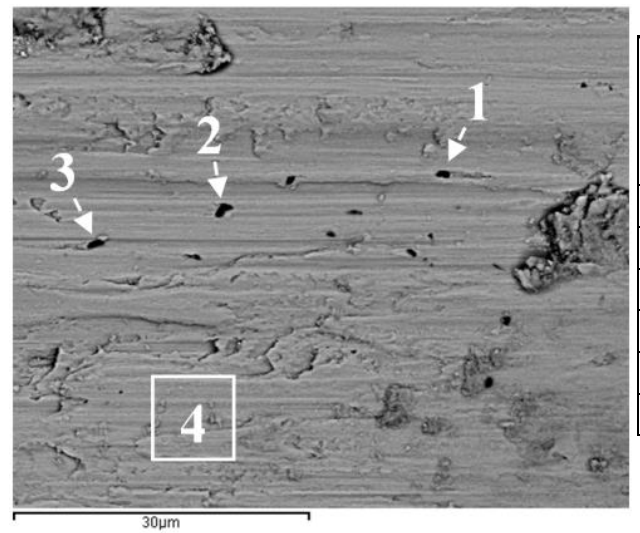

\begin{tabular}{|c|c|c|c|c|}
\hline Spectrum & \multirow{2}{*}{$\mathbf{1}$} & $\mathbf{2}$ & $\mathbf{3}$ & $\mathbf{4}$ \\
\hline $\mathbf{O}$ & & & & \\
\hline $\mathbf{A l}$ & 28.14 & 22.98 & 23.04 & 1.42 \\
\hline $\mathbf{C r}$ & 9.26 & 21.74 & 23.59 & 0.00 \\
\hline $\mathbf{M n}$ & 0.00 & 0.72 & 0.73 & 1.36 \\
\hline $\mathbf{F e}$ & 33.33 & 39.76 & 37.95 & 71.40 \\
\hline $\mathbf{N i}$ & 3.00 & 3.35 & 3.94 & 7.62 \\
\hline
\end{tabular}

Figure 7: BSE image at a 2,000x magnifications of a wear track for specimen A2 tested for $3000 \mathrm{~s}$ at a load of $3 \mathrm{~N}$ and sliding speed of $2 \mathrm{~mm} / \mathrm{s}$ and corresponding EDS analysis.

\section{Conclusions}

The current investigation aimed at correlating the influence of adding $\mathrm{Al}_{2} \mathrm{O}_{3}$ nano-particles to austenitic stainless steel with mechanical and wear properties, and changes in microstructure can be summarized in the following conclusions: 
- Incorporation of the $\mathrm{Al}_{2} \mathrm{O}_{3}$ nanoparticles was found to increase the hardness of the austenitic stainless steel but reduces the impact toughness. Furthermore, the addition of CaSi as a dispersant media has a significant effect on the particles distribution uniformity and de-agglomeration of particles, thus further increasing the hardness of the material.

- In terms of Yield and Ultimate tensile strength, reinforcement with nanoparticles has practically no effect, resulting in similar values with the base material.

- The incorporation of hard and wear resistant $\mathrm{Al}_{2} \mathrm{O}_{3}$ ceramic nano-particles gives more than an order of magnitude increase in the wear resistance of the austenitic stainless steel. Furthermore, mixing nanoparticles with the dispersive media, provides further improvements in wear resistance.

\section{Acknowledgements}

This work was done in the frame of the research program P2-0050 which is financed by the Slovenian Research Agency.

\section{References}

[1] J.R. Davis, Stainless Steels (ASM International, 1994)

[2] I. Ibrahim, F. Mohamed, E. Lavernia, J. Mater. Sci. 26,1137-1156 (1991)

[3] D. Miracle, Compos. Sci. Technol. 65, 2526-2540 (2005)

[4] J.S. Moya, S. Lopez-Esteban, C. Pecharroman, Prog. Mater. Sci. 52, 1017-1090 (2007)

[5] S.C. Tjong, Adv. Eng. Mater. 9, 639-652 (2007)

[6] P.M. Ajayan, L.S. Schadler, P.V. Braun, Nanocomposite Science and Technology (John Wiley \& Sons, 2006)

[7] Z. Zhang, D.L. Chen, Scripta Mater., 54, 1321-1326 (2006)

[8] A. Sanaty-Zadeh, Mat. Sci. Eng. A, 531, 112-118 (2012)

[9] S.R. Bakshi, D. Lahiri, Int. Mater. Rev., 55, 42-64 (2010)

[10] C. Suryanarayana, Mechanical Alloying and Milling (CRC Press, 2004)

[11] B. Murty, S. Ranganathan, Int. Mater. Rev. 43, 101-141 (1998)

[12] A. Kračun, M. Torkar, J. Burja, and B. Podgornik, Mater. Tehnol., 50, 451-454 (2016) 